\title{
BRASILEIROS, URUGUAIOS E A FINAL DA COPA DE 1950 NA TELEVISÃO BRASILEIRA: FUTEBOL, MEMÓRIA E A QUEBRA DO ESTEREÓTIPO DA FRONTEIRA DA PAZ
}

BRAZILIANS, URUGUAYANS AND THE 1950 WORLD CUP FINAL ON BRAZILIAN TELEVISION: SOCCER, MEMORY AND BREAKING THE STEREOTYPE OF A PEACEFUL BORDER

\author{
BRASILEÑOS, URUGUAYOS Y LA FINAL DE LA COPA DE 1950 EN LA \\ TELEVISIÓN BRASILEÑA: FÚTBOL, MEMORIA Y LA RUPTURA \\ DEL ESTEREOTIPO DE LA FRONTERA DE LA PAZ
}

\author{
Roberta Brandalise \\ Doutora, FACASPER \\ Email: betalise@terra.com.br
}

\begin{abstract}
Resumo
Estudamos a participação da televisão brasileira na articulação de representações sociais e de identidades culturais na fronteira Brasil-Uruguai. A partir das apropriações e usos que brasileiros e uruguaios fronteiriços fizeram das narrativas noticiosas que abordaram a final da Copa de 50, constatamos que elas colaboraram para o resgate da memória das relações uruguaio-brasileiras e para o reforço das identidades nacionais na região de fronteira. Essas narrativas mediaram as próprias relações sociais experimentadas entre os dois povos na região, por vezes colaborando para conferir um caráter de rivalidade à interação cotidiana. Assim, elas participaram da desconstrução do estereótipo da "fronteira da paz" que, frequentemente, predomina no imaginário fronteiriço e nas representações televisivas dessa fronteira ou das relações sociais uruguaio-brasileiras.
\end{abstract}

Palavras-chave: consumo de televisão; futebol; fronteira Brasil-Uruguai.

\begin{abstract}
We studied the participation of Brazilian television in the articulation of social representations and cultural identities on the Brazil-Uruguay border. Based on the appropriation of news stories about the 1950 World Cup final and the use made of them by Brazilians and Uruguayans living in the border region, we found the stories contributed towards recalling Brazilian-Uruguayan relations and reinforcing national identities in the area. Such narratives mediated the social relations between the two peoples in the region, occasionally tingeing quotidian interaction with rivalry. Therefore, they took part in deconstructing the stereotype of the "peaceful border," which was often prevalent in the border imagery and in the televised representations of the border or of the Brazilian-Uruguayan social relations.
\end{abstract}

Keywords: television consumption, soccer, Brazil-Uruguay border

\section{Resumen}

Hemos estudiado la participación de la televisión brasileña en el nudo de representaciones sociales y de identidades culturales en la frontera Brasil-Uruguay. A partir de las apropiaciones y usos que brasileños y uruguayos fronterizos hacen de las narrativas noticiosas que abordan la final de la Copa de 1950, constatamos que ellas contribuyen al rescate de la memoria de las relaciones uruguayo-brasileñas y al refuerzo de las identidades nacionales en la región de frontera. Esas narrativas disponen las propias relaciones sociales experimentadas entre los dos pueblos de la región, y por veces le confieren un carácter de rivalidad a la interacción cotidiana. De esta manera, empiezan a descomponer el estereotipo de la "frontera de la paz" que, frecuentemente predomina en el imaginario fronterizo y en las representaciones televisivas de esa frontera o de las relaciones sociales uruguayo-brasileñas.

Palabras-clave: consumo de televisión; fútbol; frontera Brasil-Uruguay. 


\section{Introdução $^{1}$}

Neste artigo apresentamos a análise de dados que levantamos e tratamos em nossa tese de doutorado (BRANDALISE, 2011), especialmente com relação à participação da televisão brasileira na vida social e cultural de brasileiros e uruguaios que vivem o cotidiano da fronteira Brasil-Uruguai, nas cidades de Santana do Livramento e Rivera - divisa sem barreiras naturais para demarcar os países.

A estratégia teórico-metodológica que utilizamos no estudo de caso (YIN, 2010) que realizamos foi desenvolvida a partir da orientação da Antropologia Cultural (GEERTZ, 1978) e dos Estudos Culturais Britânicos e Latino-Americanos (Hall, 1999; Martín-Barbero, 2001). Realizamos uma pesquisa qualitativa (LOPES, 2002), fazendo uso de entrevistas semiestruturadas (THIOLLENT, 1980), entrevistas abertas mediadas (modelo elaborado a partir da proposta de Collier (1973) e da observação participante (HAGUETTE, 1992).

Nossa amostra foi formada por doze fronteiriços que consumiam a televisão brasileira. Seis brasileiros residentes em Santa do Livramento (três mulheres e três homens, com as idades variando entre 23 e 69 anos) e seis uruguaios residentes em Rivera (três mulheres e três homens, com idades variando de 28 a 73 anos).

De acordo com a nossa amostra, a maior parte das representações televisivas relacionadas à fronteira Brasil-Uruguai, caracterizam essa região como a "fronteira da paz". Os entrevistados afirmaram também que, frequentemente, a televisão caracteriza as relações uruguaio-brasileiras como boas e constrói representações acerca do Uruguai e dos uruguaios associando o país e o seu povo ao sentido de amizade. Compreendemos que essas representações televisivas colaboram para a reafirmação cotidiana de um estereótipo positivo acerca das relações uruguaio-brasileiras - de acordo com o qual essas relações estão preponderantemente associadas à paz e à amizade -, especialmente na fronteira Santana do Livramento-Rivera, região em que as próprias cidades fronteiriças são conhecidas como "irmãs" ou "gêmeas".

\footnotetext{
${ }^{1}$ Uma versão deste artigo foi apresentada no V Colóquio Brasil-Chile de Ciências da Comunicação, evento componente do XXXV Congresso Brasileiro de Ciências da Comunicação.
} 
A partir de Lippmann (2008), compreendemos que os estereótipos têm um papel nas relações sociais. Eles são construídos ao longo da história para serem utilizados na atribuição de sentidos imediata daquilo que nos causa estranhamento. Por isso, eles existem em todas as culturas e podem ser tanto positivos quanto negativos. Entretanto, mesmo quando eles são positivos, os estereótipos constituem-se como uma supersimplificação da realidade que representam. Assim, eles podem acabar servindo para mascarar a realidade, ao invés de colaborar para o conhecimento e a compreensão dela.

No caso das narrativas televisivas relacionadas à Copa de 50, entretanto, os sentidos de paz e amizade estão ausentes. E as apropriações e usos que a nossa amostra fizeram dessas narrativas colaboraram para resgatar a memória das relações uruguaiobrasileiras - que nem sempre foram pautadas pela solidariedade ou pelos sentidos de paz e amizade. Isso coloca à prova o estereótipo de que a fronteira Santana do Livramento-Rivera é a "fronteira da paz" - um estereótipo construído historicamente e atualizado constantemente no cotidiano fronteiriço, inclusive com a colaboração da televisão brasileira.

Atentando para a realidade que encontramos em campo observamos, portanto, que as representações televisivas relacionadas ao futebol e, em especial, à final da Copa de 1950 - construídas em narrativas noticiosas da televisão brasileira - colaboram para a construção das representações que os fronteiriços brasileiros e uruguaios fazem uns sobre os outros. Fazendo-se relevantes, sobretudo, no jogo identitário que se processa na interação social cotidiana, e que é experimentado por esses povos em um território fronteiriço.

\section{A Copa de 50 no telejornalismo brasileiro e no imaginário de brasileiros e uruguaios}

Compreendemos que praticar ou acompanhar o futebol é uma forma de participar da vida nacional, de sentir-se fazendo parte de uma cultura nacional predominante, tanto no Brasil quanto no Uruguai. Nesse contexto, entendemos que a Copa de 1950 povoa o imaginário de brasileiros e uruguaios, uma vez que esse evento foi mencionado por todos os nossos entrevistados que acompanham jogos de futebol e as notícias que envolvem esse esporte. 
De acordo com nossa amostra, até o momento, o Brasil foi campeão do mundo de futebol cinco vezes e o Uruguai duas - além de somar duas medalhas olímpicas de ouro, em 1924 e 1928. O Brasil ganhou a Copa do Mundo na Suécia, em 1958, no Chile, em 1962, no México, em 1970, nos Estados Unidos, em 1994 e na Coréia e Japão, em 2002. O Uruguai venceu a Copa em seu próprio país, em 1930, e em 1950, no Brasil, derrotando os donos da casa.

Entendemos que nesse jogo da final da Copa de 50 o Brasil entrou em campo com pelo menos duas vantagens, estava jogando em casa e, em caso de empate, levaria o título. Esse contexto colaborou para que os brasileiros acreditassem que o Brasil venceria o Uruguai, mesmo antes do desenvolvimento da partida. Porém, o jogo foi vencido pelo Uruguai, e de virada. Esses fatores colaboraram para que o episódio marcasse a memória de brasileiros e uruguaios e fosse considerado, principalmente pelos primeiros, que saíram do jogo vencidos, como um momento emblemático pela frustração vivenciada. Acreditamos que se a final da Copa de 50 tornou-se um episódio emblemático, assim o foi também por causa da participação dos veículos de comunicação brasileiros, especialmente as rádios e os jornais que já anunciavam a vitória dos brasileiros.

De acordo com Halbwachs (1990), não é possível imaginar a história sem a memória coletiva de um povo, e a partir de sua obra, compreendemos que a memória da pessoa está ligada à do grupo, e esta última à esfera maior da tradição, que é a memória coletiva de cada sociedade. De acordo com o autor, é por meio da interação social e fazendo uso da linguagem que se constrói a memória. Considerando o que aprendemos com Halbwachs sobre a memória como um produto social, e atentando para o fato de que o tecer da história conta com a participação da mídia - tal como compreendemos a partir da leitura de Le Goff (2000) -, entendemos que a própria mídia é um espaço de construção e manutenção de memória.

Atentando para isso, destacamos que mesmo sessenta anos depois da vitória do Uruguai sobre o Brasil, observamos que a final da Copa de 1950 participa da memória dos fronteiriços e é atualizada no cotidiano, especialmente quando ocorrem jogos entre o Brasil e o Uruguai ou quando são realizadas representações televisivas sobre o tema, como nas narrativas jornalísticas mencionadas pelos entrevistados. 
Entre as representações televisivas contemporâneas que abordaram a Copa de 1950, encontramos no site da Globo.com algumas das narrativas ${ }^{2}$ mencionadas pela amostra sob os títulos "Morre o último jogador da seleção brasileira da Copa de 50" (Jornal da Globo, 30/10/2009, 31”), “Ghiggia, ex-atacante do Uruguai, relembra o final da Copa do Mundo de 1950" (Globo Esporte, 20/12/2009, 6’9”) e "Ex-jogador que calou o Maracanã na Copa de 50 é homenageado" (Jornal Nacional, 29/12/2009, 21").

Essas narrativas destacadas pelos entrevistados se dedicam às histórias de vida daqueles que participaram da final da Copa de 50. A frequência com que a televisão se remete à Copa de 50 - nas narrativas que envolvem futebol, uruguaios e brasileiros -, nos permite depreender que os jogadores ou atores sociais envolvidos nos eventos que determinaram o resultado da Copa de 1950 ainda têm valor-notícia.

O personagem principal da reportagem do Globo Esporte e da nota do Jornal Nacional é o ex-atacante da seleção uruguaia Ghiggia, o jogador que fez o gol da vitória sobre o Brasil na final da Copa de 50. A nota do Jornal Nacional informa que ele foi homenageado no Maracanã, deixando a marca dos seus pés na "calçada da fama" do estádio. Nessa nota o jogador é associado à tristeza brasileira com relação à Copa de 50, tal como evidencia a sequência em que o apresentador informa que Ghiggia é "responsável pelo capítulo mais triste da história do Maracanã" - vale destacar que a seriedade com que o apresentador fala sobre o evento aumenta o peso da sequência.

$\mathrm{Na}$ matéria do Globo Esporte, Ghiggia é caracterizado como "herói para os uruguaios" e "vilão para os brasileiros", ou ainda, como o "homem que silenciou o Maracanã". A reportagem também atribui à final da Copa de 1950 os sentidos de "alegria uruguaia" e "tristeza brasileira".

A reportagem do Globo Esporte propõe também o sentido de que os jogadores uruguaios entraram em campo com os "pés no chão". Sugerindo, assim, que sua postura estava embasada na realidade, em oposição às ações e expectativas irreais ou excessivamente otimistas dos jogadores brasileiros, geradas pelo contexto de entusiasmo antecipado configurado também com a colaboração da imprensa brasileira.

Associando ainda a seleção uruguaia ao sentido de "orgulho ferido", a narrativa do Globo Esporte considera a situação em que se encontravam os jogadores uruguaios

\footnotetext{
${ }^{2}$ Nesse artigo nos dedicamos, principalmente, ao estudo das apropriações e usos que nossa amostra fez dessas matérias. O discurso dessas narrativas foi analisado na íntegra na tese de doutorado, e elas também podem ser encontradas, atualmente, na biblioteca da Escola de Comunicações e Artes da Universidade de São Paulo - em um DVD, entregue anexado à tese supracitada.
} 
em solo brasileiro, em 1950: uma equipe subestimada pelos brasileiros e pela sua imprensa. Ghiggia é caracterizado como o jogador que "disse e mostrou" aos “companheiros de vestiário" que "botaram nos jornais que o Brasil já é campeão". O que faz dele mesmo uma figura relevante na atribuição do sentido de "orgulho ferido" que a própria reportagem confere à seleção uruguaia.

Com essas caracterizações, a reportagem procura distanciar-se do modo como a imprensa da época caracterizava o Brasil como "campeão", de antemão, ou ao sentido de "vitória" antecipada. A própria matéria revela que a imprensa que cobriu a Copa de 1950 chegou a publicar manchetes com verbos usados no tempo futuro "venceremos", um procedimento que consideramos incongruente com a construção de uma narrativa noticiosa e improvável na prática jornalística contemporânea.

Por outro lado, como a maioria das narrativas brasileiras sobre a Copa de 50, não esteve ausente da reportagem do Globo Esporte um discurso comum: o da atribuição de culpa aos jogadores brasileiros pela derrota. Um discurso que ao predominar acaba por distanciar o Uruguai do sentido de "vitória" ou de "glória". A reportagem do Globo Esporte explica que o goleiro Barbosa foi nomeado cidadão honorário do Rio de Janeiro, cinco meses antes de morrer, há cerca de dez anos, e a essa homenagem a narrativa atribui o sentido de "o Dia do Perdão" ou a caracteriza como "o reconhecimento do ex-goleiro paulista".

Atentando para a abordagem dessa matéria, em que a narrativa afirma que a homenagem prestada a Barbosa é "o reconhecimento do ex-goleiro paulista" e aponta, ao mesmo tempo, que trata-se do seu "Dia do Perdão", entendemos que há uma contradição presente nesse discurso. Entendemos que se a homenagem é o "reconhecimento do ex-goleiro paulista", a entrega do título de cidadão honorário do Rio de Janeiro à Barbosa não só atestaria suas qualidades de grande jogador, como sobretudo serviria de retratação (bastante tardia), por parte da sociedade brasileira, do fato de tê-lo responsabilizado injustamente (tivesse ele falhado ou não) pelo resultado do jogo e a derrocada brasileira.

Entretanto, apesar de o próprio Ghiggia enunciar com veemência nessa matéria que ele mesmo reprova a constante atribuição de culpa ao goleiro brasileiro Barbosa pelo resultado daquele jogo, na formação discursiva da narrativa predomina o sentido de que houve culpa do goleiro na derrota brasileira. Isso porque, na matéria, como em tantas outras, nomeia-se a homenagem à Barbosa como o "Dia do Perdão", ou enuncia- 
se que "esse ficou conhecido como o Dia do Perdão". Identificá-la como o "O Dia do Perdão" de certa forma macula essa homenagem e não deixa ninguém esquecer que Barbosa continua sendo considerado o grande culpado na determinação da "tristeza brasileira".

Assim, apesar de a matéria ter apresentado o ainda atual protesto de Ghiggia $^{3}$ e a fala do próprio Barbosa ${ }^{4}$ na ocasião em que foi homenageado - colaborações que evidenciam o quanto esse jogador brasileiro foi rotulado e estigmatizado no convívio social -, a formação discursiva predominante na narrativa acaba por associar Barbosa à culpa pela derrota brasileira em 1950. Até porque o sentido do perdão está associado ao de culpa - se é preciso perdoar é porque uma culpa foi atribuída e nas narrativas jornalísticas "o heterogêneo se apresenta como uma unidade graças à dominância de uma formação discursiva sobre as outras, pela vocação totalizante do sujeito (autor)" (ORLANDI, 1988, p. 60).

A matéria do Jornal da Globo também atribui a culpa pela derrota brasileira em 1950 aos jogadores brasileiros Barbosa (ex-goleiro), Bigode (ex-zagueiro) e Amaraggio (ex-zagueiro). Na nota do Jornal da Globo, o valor-notícia é a morte do jogador da seleção brasileira de 1950, Juvenal Amariggio. A matéria destaca que Amariggio morreu "doente", "solitário" e "dependia da ajuda de amigos para viver e para se locomover" como um esforço para pontuar a situação desrespeitosa e precária porque passam muitos brasileiros, principalmente idosos, um cenário que não exclui nem personagens que fazem parte da memória coletiva nacional - como é o caso específico de Amariggio, que por ter sido considerado um dos culpados pela derrota do Brasil, foi deixado à margem da sociedade brasileira.

Apesar desse esforço de cunho social mais abrangente, na formação discursiva da narrativa os jogadores brasileiros Amariggio, Bigode e Barbosa foram associados ao sentido de culpa ou culpados pela derrota nacional. Os atribuidores dessa culpa não são apontados diretamente, mas é possível compreender que o apresentador está se referindo aos brasileiros de modo generalizado. E, embora o apresentador não inclua e nem exclua a participação da mídia nessa atribuição de culpa, ao lembrar os três jogadores

\footnotetext{
3 "São os onze jogadores que ganham e os onze que perdem, não tem que buscar um culpado (...). Estive no Rio de Janeiro com Barbosa e ele me disse que era impossível viver assim apontado como culpado. Então, tem que culpar o Bigode que me marcava. Eu disse para o Barbosa que a culpa não era dele, ele fez o que era lógico, eu não, eu chutei”.

4"O que tiverem que fazer por mim, façam enquanto eu estou vivo, porque depois que eu morrer não adianta estátua, rua, não resolve nada".
} 
associando-os a essa pecha, a narrativa acaba reforçando a caracterização dos exjogadores como responsáveis por uma derrota nacional. Além disso, o fato de o próprio Barbosa ser lembrado como culpado, dez anos depois de seu falecimento, na narrativa do Jornal da Globo sobre Amariggio, nos leva a compreender que a culpabilização do ex-zagueiro segue fazendo parte do imaginário brasileiro

Apontamos ainda que nessa reportagem se constrói o sentido de que o Uruguai tornou-se campeão do mundo em 1950 como decorrência de uma "falha" brasileira e, portanto, não necessariamente pela sua competência em campo. Assim, em alguma medida, na narrativa nega-se o reconhecimento de que o Uruguai ganhou a Copa, distanciando-o do sentido de "glória", uma vez que se escolhe afirmar que foi a falha brasileira que "deu" o título ao Uruguai.

No discurso dessas narrativas noticiosas citadas pela nossa amostra, entre outros aspectos que destacamos aqui, ainda se constrói a representação de que a derrota brasileira de 1950 está relacionada à "falha" de brasileiros ou foi "culpa" de brasileiros, sendo esse o modo pelo qual tais narrativas constantemente se distanciam do sentido de "vitória" dos uruguaios. E essa frequente representação da televisão brasileira sobre a Copa de 50 medeia as relações sociais e o jogo identitário experimentado por uruguaios e brasileiros que vivem na fronteira, um espaço onde os eventos de 1950 evocam a memória coletiva e onde são produzidos sentidos diversos a partir das apropriações e usos dessas narrativas.

\section{Apropriações e usos das narrativas sobre a Copa de 50: memória e as identidades nacionais}

Para compreender as apropriações e usos que a nossa amostra fez dessas narrativas televisivas e conhecer suas produções de sentido, tal como nos sugere MartínBarbero (2001), realizamos uma "descrição densa" (GEERTZ, 1978) do discurso que brasileiros e uruguaios construíram a partir delas em nossas entrevistas. Isso tudo, a fim de atentar para como elas mediariam as relações uruguaio-brasileiras, identificando sua participação no jogo identitário que a amostra experimenta na região.

Para tanto, nos amparamos também em Hall (1990). Diferentemente de García Canclini (1990) - que ao estudar Tijuana, uma cidade mexicana que se localiza na 
fronteira do México com os Estados Unidos, considerou que a nação não é mais um aspecto tão relevante -, Stuart Hall (1999) atesta que a nação continua sendo uma categoria produtora de significados bastante relevante na contemporaneidade. De acordo com Hall, embora as identidades nacionais não subordinem "todas as outras formas de diferença" (HALL, 1999, p. 65), elas "tendem a se sobrepor a outras fontes, mais particularistas, de identificação cultural" (HALL, 1999, p. 67) - tal como pudemos observar em nosso próprio estudo com respeito às apropriações e usos que brasileiros e uruguaios fazem das narrativas sobre a Copa de 50, considerando as produções de sentido predominantes em seu discurso.

Brasileiros e uruguaios que integraram a nossa amostra se dispuseram a rever conosco as matérias da televisão brasileira sobre a Copa de 50, narrativas que eles mesmos destacaram como relevantes em seu cotidiano. Ao se apropriar das narrativas, os entrevistados comentaram que "na época, eu acredito que jogar contra nós era como ir para uma guerra, porque éramos campeões do mundo e o Brasil ainda não. Hoje, jogo entre Brasil e Uruguai é um clássico, mas se tornou um clássico depois da Copa de 50" (conforme o uruguaio Nestor, 59), e que "jogar contra o Uruguai é clássico, aqui na fronteira vira um guerra mesmo. Sempre tudo parece tão calmo, quando tem jogo só faltam se matar. Bom, às vezes, até se matam, a gente ouve falar" (conforme o brasileiro Angelo, 69).

A amostra estabelece que qualquer jogo entre o Uruguai e o Brasil tem o sentido de "clássico" por causa dos eventos da Copa de 1950. A partir da produção de sentidos dos entrevistados, compreendemos que quando ocorrem jogos entre o Brasil e o Uruguai as relações entre uruguaios e brasileiros fronteiriços mudam da cordialidade para a hostilidade, uma vez que a rotina dessa região de fronteira, comumente pacata ou "calma", passa a ser associada ao espírito de "guerra" ou de violência, como evidencia o discurso de Angelo ao apontar que "só faltam se matar. Bom às vezes, até se matam". Ou seja, em dia de jogo entre Uruguai e Brasil, as identidades nacionais são reforçadas, os limites entre os países ficam sublinhados e a socialização ocorre no sentido de gerar distanciamentos porque se caracteriza pela hostilidade.

Destacamos que o uruguaio Nestor enaltece a identidade nacional uruguaia pontuando que, em 1950, o país já era campeão do mundo e o Brasil não e que, por isso, os brasileiros da época estavam atribuindo um sentido de "guerra" para o jogo contra a celeste. Consideramos relevante contextualizar que Brasil e Uruguai já haviam se 
enfrentado em Copa do Mundo antes de 1950, porém é só na competição daquele ano que se percebe uma forte mobilização popular e da imprensa brasileira em torno do evento.

Conforme compreendemos, isso ocorreu porque no caso do Brasil "o futebol foi incorporado logo quando esta identidade [nacional brasileira] começou a ser construída [...] na década de 1930, quando Getúlio Vargas estava empenhado em construir uma nação. Particularmente, na Copa de 1938, [na França]" (BARRETO, apud MONTEIRO, 2006, p. 33). E, conforme Monteiro (2006, p.33), realmente, “Antes de 1938, duas Copas já haviam sido disputadas”, uma delas no Uruguai, em 1930, da qual "voltamos de terras uruguaias desclassificados com apenas um jogo: uma derrota para os anfitriões".

De acordo com o autor, quando chegamos em 1950, Getúlio Vargas já comemorava o dia primeiro de maio em estádios de futebol. O presidente chegou a assinar a Consolidação das Leis Trabalhistas (CLT, 1943) no estádio do Vasco, em São Januário. Sobre a seleção brasileira de futebol na época, Monteiro (2006, p. 33) afirma inclusive que "a filha de Getúlio, Alzira, era madrinha da equipe e o governante se referia aos jogadores como defensores dos interesses do país”. Segundo a caracterização do autor, a Copa de 1950, sediada no Brasil, "caiu como uma luva para dar força ao discurso de união nacional. Em três anos foi construído o maior estádio do mundo, o Maracanã" (MONTEIRO, 2006, p. 33) e outros foram erguidos pelo país, bem como "uma campanha nacional foi detonada por jornais e rádio" (MONTEIRO, 2006, p. 33).

Compreendemos então que em 1950 as atenções brasileiras estavam bastante voltadas para a final da Copa do Mundo, assim como as expectativas tinham sido elevadas em torno de uma possível vitória brasileira, também como consequência da utilização política do futebol para consolidar a identidade nacional e fortalecer o governo de Getúlio Vargas. E essa não foi a última vez que o futebol serviu aos fins políticos no Brasil. A Copa de 1970, a primeira a ser transmitida ao vivo pela televisão brasileira, conforme caracterização de Monteiro (2006), "foi a época dos noventa milhões em ação", em que o governo militar usou a "canarinha", a mais perfeita máquina de encantar e ganhar, para esconder de si mesma uma nação que levava choques nos porões da ditadura" (MONTEIRO, 2006, p. 34).

Quando ocorreu a Copa de 1950, a uruguaia Suzana tinha treze anos e o brasileiro Angelo, nove. Embora fossem bastante jovens na época, eles fazem parte de 
uma das gerações que viveu o contexto da final da Copa do Mundo de 1950 e, ao assistirem as narrativas televisivas, colaboraram conosco partilhando suas memórias. Suzana nos contou que "todos os brasileiros estavam convencidos de que eram campeões, aquilo dava uma raiva, eu lembro do meu pai furioso com isso e depois foi uma festa, aqui teve muita briga, todos exaltados" (Suzana, 73) e Angelo nos contou que "eu era pequeno, lembro do meu pai, meu pai me levou para ouvir o jogo no rádio, num mercado de secos e molhados que ficava perto da Igreja. Não tínhamos rádio, quase ninguém tinha, ai... a decepção que ele ficou, a tristeza, aquilo me marcou assim, tu não pode imaginar" (Angelo, 69).

Observamos que a final da Copa de 1950 imediatamente remete os dois entrevistados as suas figuras paternas. Com isso, compreendemos que os sentidos que eles atribuem a essa experiência também foram construídos a partir do que eles perceberam que os seus pais experimentaram ou por meio da mediação familiar. Considerando a memória da amostra, compreendemos que o contexto fronteiriço da época estava associado ao sentido de confronto ou de "briga" e os ânimos ficavam "exaltados". Os brasileiros estavam "convencidos" da vitória e os uruguaios, como Suzana e seu pai, tinham o orgulho ferido, uma vez que ela estabelece que sentia "raiva" e que ele estava "furioso". Ainda naquele contexto, o resultado do jogo gerou "tristeza" ou "decepção" brasileira, como fica evidente nas produções de sentido do brasileiro Angelo sobre o estado emocional de seu pai e o quanto isso significou para ele mesmo, e desencadeou a "festa" uruguaia, conforme pontua Suzana. Então, compreendemos que os eventos que envolveram o resultado da Copa de 1950 geraram o enaltecimento das identidades nacionais na fronteira - e não da identidade fronteiriça - e, ao se apropriarem das narrativas televisivas, os entrevistados atualizaram o sentido de rivalidade atribuído as suas memórias.

A amostra também utilizou as narrativas para caracterizar os povos brasileiro e uruguaio, delimitando suas diferenças. Os uruguaios comentaram que "eu penso que os brasileiros são mais soberbos do que nós, em tudo, no futebol muito mais, hoje são campeões do mundo várias vezes, mas naquela época não tinham nenhum título" (Emília, 53) e que "se achavam melhores do que nós, é claro que aquilo machucou, temos o nosso orgulho e até hoje ter ganhado do Brasil em sua casa fez com que nos respeitassem mais, para nós ainda é a glória” (Nestor, 59). Os brasileiros comentaram que "o uruguaio é mesmo um povo humilde, eles são muito educados, muito mais do 
que nós, eu acho que é isso o que podemos aprender mesmo com eles. Aqui na fronteira, convivendo isso é possível" (Thaísa, 55) e que "foi uma lição e tanto, realmente uma partida se ganha em campo, e por isso mesmo não se ganha lembrando das glórias do passado, hoje o Brasil disparou na frente do Uruguai, não se compara" (Sérgio, 42) e ainda que "é, mas foi mesmo a derrota mais triste que sofremos em casa, aí quem ficou com o orgulho ferido fomos nós, perdemos quando achávamos que não era possível, mas não queríamos dar o braço a torcer para os uruguaios e ainda não damos" (Célio, 58).

Os uruguaios caracterizam os brasileiros como "mais soberbos" ou "se achavam melhores do que nós". Contextualizam que isso ocorre principalmente no futebol, ao enfatizarem o "muito mais", porém nos dão pistas de que atribuem esse sentido aos brasileiros generalizadamente, ao dizerem "em tudo". A entrevistada uruguaia reconhece que atualmente os brasileiros são "campeões [...] várias vezes", mas faz a ressalva de que em 1950 "não tinham nenhum título". Assim, ela procura fundamentar a atribuição do sentido de "soberbos" aos brasileiros. Nestor pontua que essa postura dos brasileiros "machucou [...] o nosso orgulho", revelando que a identidade nacional uruguaia realmente está em jogo quando se trata de futebol (em especial o episódio da final da Copa de 1950), e que a vitória celeste "fez com que nos respeitassem mais" e "ainda [hoje] é glória". Ou seja, essa vitória do Uruguai "ainda" é um recurso utilizado atualmente pelos uruguaios para interagir com os brasileiros.

Percebemos que nessas colaborações há pistas de que os uruguaios não se sentem respeitados ou valorizados pelos brasileiros na mesma medida em que oferecem respeito ou valorização. Isso se evidencia quando apontam que o brasileiro é soberbo ou excessivamente orgulhoso. Portanto, ter derrotado o Brasil na Copa de 50 - quando os brasileiros também agiam de modo soberbo, ao acreditarem que o título estava ganho é fundamental para lembrar os vizinhos de que o povo uruguaio tem valor e deve ser respeitado. Compreendemos que a memória dessa derrota é utilizada no cotidiano da fronteira como um mecanismo que serve para manter o equilíbrio nas relações sociais fronteiriças, freando o que os uruguaios consideram como um excesso de orgulho por parte dos brasileiros.

Ao se apropriar das narrativas, uma entrevistada brasileira caracteriza os uruguaios como um povo "humilde" ou "educado", estabelecendo uma relação de alteridade, uma vez que ela utiliza a expressão "muito mais do que nós". 
Compreendemos que Thaísa não considera a humildade uma característica típica de seu próprio povo e essa representação nos parece congruente com a que os uruguaios formulam sobre os brasileiros, em que os caracterizam como demasiadamente orgulhosos. Ao produzir esses sentidos, Thaísa distingue uruguaios de brasileiros e atribui a estes a necessidade de "aprender com" aqueles. Ou seja, para ela, a educação e a humildade do povo uruguaio são qualidades pelas quais primam os vizinhos diferentemente dos brasileiros -, sendo portanto positiva a identidade que ela atribui aos uruguaios, estando ausente o sentido de rivalização.

Por outro lado, seu marido Célio confirma que "achávamos que não era possível" perder para o Uruguai, bem como caracteriza que a Copa de 1950 realmente foi a "derrota mais triste que sofremos em casa" e pontua que "aí quem ficou com o orgulho ferido fomos nós", revelando também que a identidade nacional de fato está em jogo quando se trata de futebol. Diferentemente da formulação de Thaísa, a formação discursiva do comentário de Célio produz o sentido de rivalização. Isso ocorre quando ele enfatiza que "não queríamos dar o braço a torcer para os uruguaios e ainda não damos". "Dar o braço a torcer" é uma metáfora que nos remete aos processos que simbolicamente fazem dos iguais, desiguais. Nesse sentido, a queda de braço torna o “jogo de futebol" equivalente à "guerra". Com essa produção de sentido, compreendemos que Célio procura, mesmo na atualidade, não validar a vitória do Uruguai sobre o Brasil, uma vez que ele enfatiza que "ainda não damos" o braço a torcer e identifica os uruguaios como rivais.

O outro entrevistado brasileiro se apropria das narrativas ironicamente. Ele inicialmente concorda que os brasileiros aprenderam "uma lição e tanto" e que "uma partida se ganha dentro de campo". Em seguida, ele nos permite compreender que utiliza a narrativa para enfatizar, a partir da sequência "por isso mesmo", a superioridade brasileira no todo da história do futebol mundial e o anacronismo implícito em qualquer tentativa de se fazer hoje uma comparação entre o futebol brasileiro e uruguaio. Sérgio canaliza sua ironia ao dizer que "não se ganha lembrando das glórias do passado", referindo-se ao Uruguai que teve um grande futebol no passado e que não se manteve em alta desde então, ao dizer que "o Brasil disparou na frente do Uruguai” ou que "não se compara". Compreendemos que a formação discursiva desse comentário produz o sentido de hostilidade, uma vez que ele procura desqualificar os uruguaios como rivais. 
Sobre a situação vivida por Amariggio, um entrevistado uruguaio comentou que é "um absurdo isso, um jogador de Copa do Mundo morrer miserável e doente, é uma ingratidão, o homem representou o seu país" (Nestor, 59) e uma entrevistada brasileira disse "ai, coitado, gente. Para que torturar o homem a vida toda desse jeito, parece castigo" (Maria Eduarda, 23). Compreendemos que ao se apropriar da narrativa, a amostra atribuiu o sentido de "ingratidão" para o desamparo experimentado por Amariggio. E ainda apontamos que a narrativa causou surpresa ao entrevistado uruguaio. De acordo com suas produções de sentido, alguém que representa o próprio país merece algum tipo de deferência, sendo o contrário disso considerado por ele como uma situação ilógica ou um "absurdo". O caso de Amariggio também suscita pena, isso fica evidente quando a entrevistada brasileira diz "ai, coitado". Essa produção de sentido também está associada à ideia de protesto, porque a entrevistada fala como se estivesse chamando a atenção dos que estão a sua volta ou a toda "gente". Quando a entrevistada brasileira questiona "para que torturar o homem a vida toda" ou aponta que "parece castigo", compreendemos que, além do seu tom de protesto, ela também está atribuindo um caráter de precariedade e desrespeito para com o final da vida de Amariggio, pelo fato de ele ainda ser (e ter sido "a vida toda") considerado culpado por alguma coisa no imaginário social brasileiro, uma vez que o punir ou o "torturar" ou o "castigo" estão relacionados ao sentido de "culpa" construído nas narrativas brasileiras.

Ainda sobre a atribuição de culpa aos jogadores brasileiros pela derrota para o Uruguai e o chamado "Dia do Perdão" de Barbosa, um entrevistado uruguaio comenta que "perdoaram nada, ainda culpam o Barbosa, o Bigode e o Amariggio e quem mais puderem porque não querem admitir que fomos melhores, fomos melhores do que o Brasil, vencemos por nosso próprio mérito" (Eduardo, 28). Ao se apropriar das narrativas, ele resiste ao discurso televisivo, especialmente quando este insiste no "Dia do Perdão", e se posiciona dizendo "perdoaram nada", referindo-se não só a Barbosa, mas também a Bigode, Amariggio e "quem mais puderem" culpar. O entrevistado uruguaio utiliza as narrativas para produzir os sentidos de que "não querem admitir que fomos melhores do que o Brasil" ou que "vencemos por nosso próprio mérito". Assim, compreendemos que, ainda na atualidade, a insistência das narrativas brasileiras em abordar a derrota de 1950 culpando sistematicamente os jogadores brasileiros, de fato, distancia a associação dos uruguaios ao sentido de vitória, sendo que esse não reconhecimento pleno da superioridade uruguaia por parte dos brasileiros povoa o 
imaginário social uruguaio. No contexto fronteiriço, esse sentido colabora para fortalecer as identidades nacionais, em detrimento da identidade fronteiriça, gerando distanciamento entre brasileiros e uruguaios.

\section{Identidade fronteiriça:}

\section{memória de colaborações regionais em torno do futebol}

Ocorre que o jogo entre as identidades culturais na fronteira que estudamos é situacional - tal como Stuart Hall (1999) utiliza o conceito -, e a realidade fronteiriça é multimediada - de acordo com o que aprendemos com Martín-Barbero (2001). Dependendo das situações vividas no cotidiano, é possível observarmos as identidades nacionais sendo colocadas em evidência em detrimento das outras; entretanto, mesmo diante da tendência assimilacionista das culturas nacionais, elas nem sempre são mais relevantes do que as outras no jogo identitário. Assim como, dependendo da situação que se apresenta à amostra, é o sentimento de pertença à mesma região fronteiriça (identidade regional ou fronteiriça) que pode ser percebido em evidência, em detrimento das outras identidades.

Atentando para a mobilidade e a pluralidade característica do jogo identitário que se desenvolve nessa fronteira, bem como para as diversas mediações que participam dos processos de construção de sentidos que os fronteiriços elaboram ao se apropriarem e utilizarem as narrativas da televisão brasileira que eles consomem, podemos observar também momentos em que a identidade regional ou fronteiriça é manifestada de modo mais fortalecido no discurso de nossos entrevistados.

Como, por exemplo, quando o uruguaio Eduardo comentou que "quando algum time tem [tinha] que jogar com o Grêmio, joga[va] aqui em Rivera" e o brasileiro Sérgio disse que "o estádio do time daqui [o Grêmio] é [era] o de Rivera, é [era] o nosso estádio". O Grêmio do qual falam nossos entrevistados é o time de futebol mais conhecido como Grêmio Santanense, de Santana do Livramento. O time chegou a conquistar o campeonato gaúcho em 1937 e, depois de apresentar um bom desempenho na década de 90, na primeira divisão do futebol gaúcho, caiu para a série B (em 1997) desde 2003 o time está licenciado das competições oficiais. Seu nome completo é Grêmio Foot-Ball Santanense e foi fundado em 1913, após a criação do primeiro time 
de futebol da cidade e terceiro mais antigo do Brasil - o Esporte Clube 14 de Julho, de 1902, nascido na faixa de fronteira entre Rivera e Santana do Livramento, onde existe hoje uma área de preservação chamada Parque Internacional. Ambos surgiram como consequência da proliferação de times uruguaios na fronteira e, atualmente, cada qual tem seu estádio de futebol, o Honório Nunes ( 8 mil pessoas) e o João Martins (5 mil pessoas), respectivamente. Entretanto, de acordo com a amostra, quando outro time gaúcho viajava para a fronteira a fim de jogar com o Grêmio Santanense, era comum a partida ocorrer no estádio de futebol Atilio Paiva de Olivera, de Rivera, que tem capacidade para acomodar trinta mil pessoas e é o segundo maior do Uruguai.

O fato de um time brasileiro realizar seus jogos em um estádio uruguaio, sendo considerado pelos brasileiros "o nosso estádio", é um exemplo, entre outros, das corriqueiras colaborações institucionais entre Santana do Livramento e Rivera. Apontamos também que, enquanto redigíamos nossa tese, em 30/1/2011 os times gaúchos de futebol Grêmio e Internacional disputaram um jogo pelo Campeonato Gaúcho no estádio Atilio Paiva, de Rivera. Conhecido como Gre-Nal, o jogo entre esses dois times é considerado o maior clássico do futebol do Rio Grande do Sul. A realização de um Gre-Nal no Uruguai, de parte do campeonato gaúcho na cidade de Rivera (Grêmio e Internacional já haviam disputado partidas da competição nesse estádio), ou mesmo de um jogo do Internacional pela Copa Libertadores da América, é um relevante exemplo de colaboração entre uruguaios e brasileiros.

O brasileiro Sérgio ainda comentou que "aqui tem uruguaio torcendo pelo Inter, pelo Grêmio, também tem brasileiro que torce para time uruguaio, mais o River Plate" (Sérgio, 42). De fato, na fronteira, observamos uruguaios usando camisetas de times brasileiros, especialmente dos gaúchos Internacional e Grêmio, e ainda vimos brasileiros vestindo camisetas do River Plate e do Peñarol, de Montevideo, e ainda, um usando a camiseta do Tacuarembó, da cidade uruguaia de mesmo nome.

Compreendemos que, ao se apropriarem das narrativas televisivas sobre o futebol, os entrevistados também produzem sentidos que reforçam a identidade fronteiriça, sublinhando as colaborações entre uruguaios e brasileiros no que diz respeito ao incentivo do futebol na região de fronteira, como no caso do estádio de Rivera, que é utilizado pelo time de Santana do Livramento, ou apontando que os fronteiriços, muitas vezes, torcem pelos mesmos times, independentemente das agremiações serem uruguaias ou brasileiras. Entretanto, isso ocorre apenas quando as 
disputas de futebol em questão não colocam uruguaios de um lado do campo e brasileiros do outro.

\section{Considerações finais}

Compreendemos que as representações construídas pelos fronteiriços no âmbito do futebol, a partir de suas apropriações das narrativas televisivas, participam do jogo identitário fronteiriço da seguinte forma. Embora existam produções de sentido que reforçam a identidade fronteiriça, como quando se pontuam as colaborações no futebol regional ou quando os fronteiriços dos dois países torcem para os mesmos times, sejam eles brasileiros ou uruguaios, entendemos que essas representações só se sustentam enquanto as disputas de futebol em questão não os colocam em lados opostos do campo. Assim, tal como evidenciamos ao longo deste artigo, são predominantes as produções de sentido nas quais o futebol é utilizado para o cultivo das identidades nacionais na fronteira e para o estabelecimento de relações de alteridade entre uruguaios e brasileiros.

O contexto fronteiriço, caracterizado pela constante interação entre uruguaios e brasileiros e marcado pela memória da Copa de 1950, bem como por todas as produções de sentido que envolvem esse evento - desde o qual o confronto entre Brasil e Uruguai tornou-se um clássico -, medeia o modo como eles se apropriam do discurso televisivo sobre o futebol. Assim como as narrativas televisivas participam desse contexto, sendo utilizadas para o reforço das identidades nacionais ou para sublinhar os limites simbólicos entre os países. E, principalmente, na desconstrução do estereótipo da “fronteira da paz" ou da "amizade", uma vez que quando ocorrem jogos entre o Brasil e o Uruguai, as relações entre os fronteiriços são associadas predominantemente aos sentidos de hostilidade ou rivalidade.

Nesse sentido, a fim de pontuar a fragilidade desse estereótipo, é relevante destacar finalmente que enquanto ocorria a Copa do Mundo de $2010^{5}$, conforme

\footnotetext{
${ }^{5}$ A seleção uruguaia terminou a Copa de 2010 em um destacado quarto lugar, demonstrando um ótimo desempenho, depois de quatro décadas sem figurar entre os dez melhores colocados ou sequer classificar-se para participar do evento, inclusive com o atacante Diego Forlán - filho de Pablo Forlán, lateral direito uruguaio que jogou seis anos no São Paulo Futebol Clube e que com os companheiros do Peñarol de Montevideo conquistou a Copa Libertadores da América e o Campeonato Mundial de Clubes em 1966 - sendo eleito o melhor jogador da Copa pela FIFA
} 
informa o canal de notícias esportivas da televisão por assinatura, a ESPN, no dia 2/7/2010, "Policiais uruguaios fizeram um cordão na fronteira com o Brasil para isolar as provocações entre os torcedores da celeste e os brasileiros pouco antes do término do jogo que eliminou a seleção pentacampeã do mundo. A informação é do jornal uruguaio Ovación, que relatou ainda que a ação já servia de preparação para uma eventual celebração do Uruguai, que deve estar acontecendo neste momento. [...]". Consideramos queessa narrativa também evidencia a relação de rivalidade entre o Brasil e o Uruguai e confirma que, nesse tipo de situação experimentada no cotidiano e retratada na televisão, o estereótipo de "fronteira da paz" não se sustenta.

\section{REFERÊNCIAS BIBLIOGRÁFICAS}

BRANDALISE, Roberta. A Televisão Brasileira nas Fronteiras do Brasil com o Paraguai, a Argentina e o Uruguai. Um estudo sobre como as Representações Televisivas participam da articulação das Identidades Culturais no cotidiano fronteiriço. Tese de Doutorado, Ciências da Comunicação, Escola de Comunicações e Artes (ECA), Universidade de São Paulo (USP), São Paulo: Acervo da USP, 2011.

CANCLINI, N. G. Culturas Híbridas. México: Grijalbo, 1990.

COLLIER JR, J. Antropologia Visual: a fotografia como técnica de pesquisa antropológica. São Paulo: EPU/EDUSP, 1973.

GEERTZ, C. A Interpretação das Culturas. Rio de Janeiro: Zahar, 1978.

HAGUETE, T. M. F. Metodologias qualitativas na Sociologia. Petrópolis: Vozes, 1992.

HALBWACHS, M. A memória coletiva. São Paulo: Edições Vértice, 1990.

HALL, S. A identidade cultural na pós-modernidade. Rio de Janeiro: DP\&A, 1999.

LE GOFF, J. História e Memória. Vol. I e vol. II. Lisboa: Edições 70, 2000.

LIPPMANN, Walter. Opinião Pública. Petrópolis: Vozes, 2008

(Fédération Internationale de Football Association). Já a seleção brasileira, considerada uma das favoritas, teve uma participação aquém da esperada. 
LOPES, M. I. V. Pesquisa em Comunicação. São Paulo: Loyola, 2002.

MARTÍN-BARBERO, J. Dos Meios às Mediações: Comunicação, Cultura e Hegemonia. Rio de Janeiro: Editora UFRJ, 2001.

MONTEIRO, D. As Razões do Futebol (ou como explicar o que sinto quando me abraço aos prantos com um total desconhecido). In: Raiz, p. 24-35, São Paulo: junho de 2006.

ORLANDI, E. P. Discurso e leitura. São Paulo: Cortez, 1988.

THIOLLENT, M. Crítica Metodológica, Investigação Social e Enquete Operária. São Paulo: Polis, 1980.

YIN, R. K. Estudo de Caso - Planejamento e Métodos. Porto Alegre: Bookman, 2010 . 